\title{
Use of a Front-Viewing Scope After Failure to Cannulate a Deep Intradiverticular Papilla
}

Paradiverticular papillae are usually easy to cannulate (1). In some cases, however, the papilla is located deep inside the diverticulum, often lying at the bottom of it, making the cannulation difficult (2). Some techniques that may help in this situation have been described $(3,4)$. The lower edge of the diverticulum may sometimes also mask the papilla when the scope remains in the lumen. When the scope is bent upward, the view is too vertical. In addition, the initial segment of the duct is often more horizontal than usual, and the direction of the cannula may therefore be too vertical. On the other hand, the distance between the lumen and the papilla means that a front-viewing scope can be bent upward to match the direction of the ducts (Figure 1).

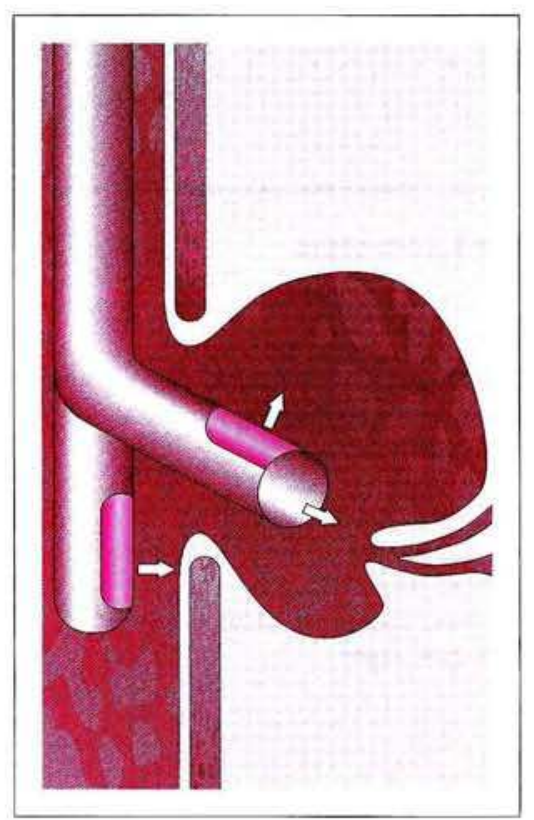

Figure 1: Positioning the front-viewing scope.
Case 1. A frail 74 -year-old man presented in 1989 with biliary pain and elevated enzyme levels. An attempted endoscopic retrograde cholangiopancreatography (ERCP) failed, since the papilla was located deep inside a diverticulum. In 1994, a recurrence of symptoms led to a further failed attempt to carry out ERCP. However, use of an Olympus XQ-20 front-viewing scope, bent upward into the diverticulum via the short route, allowed easy cannulation. The opacification failed to show any stone.

Case 2. A very frail 87-year-old man presented with cholangitis in 1997. At ERCP, it was not possible, despite repositioning both the scope and the patient, to position the duodenoscope facing the papilla, which was lying deep inside a narrow diverticulum. However, using a Fuji FP-7 front-viewing scope via the long route made it possible to position it exactly facing the papilla, without any significant bending. Cannulation was easy using an almost straight, long-nosed sphincterotome, and sphincterotomy was also easy after returning via the short route.

With intradiverticular papillae, therefore, it is worth trying out a front-viewing scope after failure using the routine side-viewing scope. The long nose of the sphincterotome maintains the correct direction if cutting is required.

\section{B. Maroy}

Maison Médicale de Lunesse,

L'Isle d'Espagnac, France

\section{References}

1. Chang-Chien CS. Do juxtapapillary diverticula of the duodenum interfere with cannulation at endoscopic retrograde cholangiopancreatography? Gastrointest Endosc 1987; 33: 298-300.

2. Leivonen MK, Halttunen JAA, Kivilaakso EO. Duodenal diverticulum at endoscopic retrograde cholangiopancreatography: analysis of 123 patients. Hepato-Gastroenterology 1996; 43: 961-3.

3. Sherman S, Haves RH, Lehman GA. A new approach to performing endoscopic sphincterotomy in the setting of a juxtapapillary duodenal diverticulum. Gastrointest Endosc 1991; 37: 353-5.

4. Tantau M, Person B, Burtin P, Boyer J. Duodenal diverticula and ERCP: a new trick. Endoscopy 1996; 28: 326.

Corresponding Author

B. Maroy, M.D.

Maison Médicale de Lunesse

24, rue Chabernaud

F-16340 L'Isle d'Espagnac

France

Fax: $+33-545942500$ 